\title{
Produção científica no campo da Gastronomia: em busca de uma configuração
}

\author{
Scientific production in the field of Gastronomy: in search of a \\ configuration
}

\section{Producción científica en el campo de la Gastronomía: en búsqueda de una configuración}

\author{
Rafael Cunha Ferro \\ Mestre em Hospitalidade pela Universidade Anhembi Morumbi \\ Professor da Universidade do Vale do Paraíba na graduação em Gastronomia \\ rafaelferro@univap.br
}

Orcid: https://orcid.org/0000-0002-9063-8395

\begin{abstract}
Mirian Rejowski
Livre docente em Turismo, Doutora e Mestre em Ciências da Comunicação pela Universidade de São Paulo (USP).
\end{abstract}

Professora Titular da Universidade Anhembi Morumbi e Professora Sênior na USP, com atuação na graduação e pós-graduação em Hospitalidade e Turismo.

mirwski@gmail.com

Orcid: https://orcid.org/0000-0001-6135-0221

Data de submissão:07/03/2018 - Data de aceite:09/05/2018

\begin{abstract}
RESUMO: Esta pesquisa exploratória-descritiva possui natureza documental e se caracteriza como um estudo de estado da arte de documentos originários de programas de pós-graduação stricto sensu de qualquer área do conhecimento em âmbito nacional, relacionados diretamente com a Gastronomia. Como objetivo principal, pretendeu-se investigar a formação do campo de conhecimento da Gastronomia no Brasil a partir da sistematização da sua produção acadêmica em nível de pós-graduação. A amostra dessa pesquisa contou com 223 documentos - teses (13\%) e dissertações (87\%) datados de 1999 e 2016 -, cujos dados foram tratados pela análise de conteúdo. Com base no tipo de documento, instituição de ensino superior, nome do programa e ano de defesa, foi possível classificar os documentos em 27 áreas do conhecimento, com maior concentração em Turismo e Interdisciplinar, e em 7 grandes áreas do conhecimento, com destaque para Ciências Sociais Aplicadas. Os títulos, resumos, objetivos e palavras-chave foram utilizados para categorizar os documentos em 12 aspectos que foram agrupados em três abordagens: comercial, não comercial e de saúde. Em média, 3 a cada 5 documentos versam sobre temáticas voltadas aos aspectos não comerciais da Gastronomia. Com essa sistematização, elaborou-se um modelo preliminar de abordagens temáticas do campo da Gastronomia, que reforça a natureza multi e interdisciplinar da pesquisa nesse campo emergente em construção.
\end{abstract}

PALAVRAS-CHAVE: Gastronomia. Produção científica. Dissertações e Teses. Configuração teórica. 


\begin{abstract}
This exploratory-descriptive research is documentary in nature, and is characterized as a state-of-the-art study of documents originating from stricto sensu programs in any area of knowledge, within the country, directly related to Gastronomy. The main objective was to investigate the training offered in Brazil in the field of Gastronomy, based on a systematization of its academic production at graduate level. The research sample included 223 documents - theses (13\%) and dissertations (87\%) dating from 1999 and 2016. The contents of the documents were submitted to content analysis. Based on the type of document, institution of higher education, name of the program and year of defense, it was possible to classify the documents into 27 areas of knowledge, with a greater concentration in Tourism, and Interdisciplinary fields, and in 7 major areas of knowledge, with most in the area of Applied Social Sciences. The titles, abstracts, objectives and keywords were used to categorize the documents into 12 aspects, which were then grouped into three approaches: commercial, non-commercial and health. On average, 3 out of 5 documents dealt with themes related to non-commercial aspects of Gastronomy. Based on this systematization a preliminary model was created of thematic approaches in the field of Gastronomy field, reinforcing the multi- and interdisciplinary nature of research in this emerging field.
\end{abstract}

KEY-WORDS: Gastronomy. Hospitality. Scientific production. Dissertations and theses. Theoretical configuration.

RESUMEN: Esta investigación exploratoria descriptiva posee naturaleza documental y se caracteriza como un estudio de estado del arte de documentos originarios de programas de posgraduación stricto sensu en cualquier área del conocimiento en ámbito nacional, relacionados directamente con la Gastronomía. Como objetivo principal, se pretendió investigar la formación del campo de conocimiento de la Gastronomía en Brasil a partir de la sistematización de su producción académica en nivel de posgraduación. La muestra de esta investigación contó con 223 documentos - tesis (13\%) y disertaciones (87\%) fechados de 1999 a 2016 -, cuyos datos fueron tratados por el análisis de contenido. Con base en el tipo de documento, institución de enseñanza superior, nombre del programa y año de defensa, fue posible clasificar los documentos en 27 áreas del conocimiento, con mayor concentración en Turismo e Interdisciplinar, y en 7 grandes áreas del conocimiento, con destaque para Ciencias Sociales Aplicadas. Los títulos, resúmenes, objetivos y palabras clave fueron utilizadas para categorizar los documentos en 12 aspectos que fueron agrupados en tres abordajes: comercial, no comercial y de salud. En promedio, 3 de cada 5 documentos versan sobre temáticas relacionadas a los aspectos no comerciales de la Gastronomía. Con esa sistematización, se elaboró un modelo preliminar de abordajes temáticas en el campo de la Gastronomía, que refuerza la naturaleza multi e interdisciplinar de la investigación de este campo emergente en construcción.

PALABRAS CLAVE: Gastronomía. Producción científica. Disertaciones y Tesis. Configuración teórica.

\section{INTRODUÇÃO}

Alimentar-se é um ato biologicamente vital, mas moldado conforme condicionantes materiais (fisiológicos, ecológicos, geográficos, tecnológicos, econômicos, etc.) e condicionantes não materiais/simbólicas (sociais, culturais e históricos) (Poulain, 2002). A evolução histórica na maneira de se alimentar trouxe consigo o surgimento do campo da Gastronomia advindo principalmente de restaurantes e outros serviços (Bueno, 2016).

Apesar da atenção às técnicas aplicadas na transformação dos alimentos, a Gastronomia está sujeita, assim como a própria Alimentação, às influências de diversas dimensões da vida social (religiosa, econômica, jurídica, política, cultural, etc.) e biológica do ser humano. Assim o conhecimento produzido nesse campo é resultante da contribuição de diversas disciplinas científicas. É um campo de estudos denominado multi e interdisciplinar, composto por um conjunto de disciplinas que trabalha de maneira isolada ou em conjunto para discorrer sobre temas ligados ao ato de produzir, transformar e comer alimentos.

Assim, adotou-se neste estudo a Gastronomia como sendo a interpretação de chefes de cozinha e outros profissionais do setor de alimentos e bebidas sobre os símbolos associados à Alimentação por meio da combinação de técnicas culinárias em busca da perfeição estética das refeições. A Gastronomia é tratada como vanguarda ou memória alimentar, combinando e alterando símbolos ou resgatando e promovendo identidades alimentares perdidas ou em extinção (Collaço, 2013), sendo esse fenômeno comunicado entre os 
profissionais e entre profissionais e público geral por intermédio das mídias e dos estabelecimentos gastronômicos (Bueno, 2016).

Mediante a leitura de diversas publicações técnico-científicas que versam sobre o estudo da Gastronomia e Alimentação, é possível observar que os diversos conceitos aplicados nestes textos demonstram a existência de conhecimentos distintos sobre as temáticas da Gastronomia e da Alimentação. Diferentes áreas com seus próprios métodos e abordagens teóricas parecem disputar um espaço para explicar este fenômeno sob a sua ótica no âmbito da noção de campo científico ou de conhecimento descrito por Bourdieu (1976).

Percebe-se com isso que o conhecimento científico acerca da Gastronomia ainda não foi devidamente sistematizado quanto às contribuições que recebe de outras disciplinas ou campos e às suas respectivas temáticas, como ocorre no campo do Turismo, no qual Jafari e Ritchie (1981) e Tribe (1997) propuseram seus modelos.

Esta pesquisa poderá suprir este gap oferecendo informações para um desenvolvimento científico ordenado do campo da Gastronomia. Optou-se por realizar uma pesquisa de caráter documental, com foco nas dissertações de mestrado e teses de doutorado como objetos de estudo. Como esses documentos são resultados de pesquisas científicas densas e orientadas por pesquisadores capacitados, reconhece-se a sua relevância na vanguarda da produção do conhecimento de qualquer área.

Diante desse cenário, delinearam-se os objetivos a fim de caracterizar as dissertações e as teses sobre Gastronomia produzidas no Brasil; analisar e categorizar o conteúdo dessas pesquisas nas áreas disciplinares que contribuem para a formação desse campo; identificar nessas áreas as temáticas específicas do estudo da Gastronomia, classificando-as em temas e, por fim, propor uma configuração de sua estrutura e componentes.

O primeiro tópico inicia-se com o surgimento e a regulamentação da educação superior em Gastronomia no Brasil, buscando as origens do conhecimento em Gastronomia no ensino superior e também o desenvolvimento da oferta desse curso em âmbito nacional. Encerra-se o capítulo com a relevância da educação no desenvolvimento da pesquisa científica. No tópico seguinte se discorre sobre a Teoria dos Campos de Bourdieu (1976; 1998), que serviu como ótica para toda essa pesquisa.
O terceiro tópico apresenta o percurso metodológico para o tratamento de 223 documentos extraídos do Banco de Teses da CAPES (Coordenação de Aperfeiçoamento de Pessoal de Nível Superior) resultantes da busca pelo termo "Gastronomia", com um recorte entre os anos de 1999 e 2016, e que apresentaram abordagem direta com as temáticas envolvidas com Alimentação e/ou Gastronomia. Aplicaramse os métodos de estado da arte (Ferreira, 2002; Romanowski \& Ens, 2006) e análise de conteúdo (Bardin, 2011) sobre os seguintes dados bibliográficos de conteúdo: a) título; b) resumo; c) palavras-chave; e forma: a) tipo de documento (dissertação ou tese); b) origem/ instituição/faculdade; c) nome do programa; d) ano de defesa.

No quarto tópico apresentam-se os resultados da pesquisa, discutindo-os em relação ao referencial teórico de fundamentação a partir da caracterização geral dos documentos da amostra, da análise temático do seu conteúdo e da proposta de um modelo preliminar do campo da Gastronomia no Brasil.

\section{EDUCAÇÃO E PESQUISA EM GASTRONOMIA NO BRASIL}

No Brasil, o ensino superior na área de turismo e hospitalidade seguiu uma sequência iniciada pelo curso de Turismo em 1970, em seguida, em 1978, tem-se a criação do primeiro curso de Hotelaria na Universidade de Caxias do Sul (RS), pela iniciativa de Geraldo Castelli e voltado principalmente ao enfoque operacional relacionado a alimentos e bebidas (Campos, 2001). Somente em 1999 os cursos de Eventos e Gastronomia foram criados, sendo o curso de Gastronomia ofertado nas modalidades bacharelado, sequencial e tecnólogo, em resposta à Lei de Diretrizes e Bases da Educação de 1996 (Sogayar \& Rejowski, 2014).

Posteriormente, em 2006, os cursos superiores de tecnologia em Gastronomia ganharam um aporte para a construção de seus Projetos Pedagógicos de Curso (PPC), com base nas atividades e nas competências dispostas no Catálogo Nacional dos Cursos Superiores de Tecnologia (Ministério da Educação e Cultura [MEC], 2016), disponibilizado pelo Ministério da Educação.

Desde 1999 a oferta do ensino superior em Gastronomia apresentou um crescimento vertiginoso até a pesquisa realizada por Rocha 
(2016), no de 2014. Em 2017, o portal do e-MEC ${ }^{1}$ contabilizava 218 cursos superiores de Gastronomia, sendo 201 ofertados no sistema privado, com um crescimento de $99 \%$ em apenas 3 anos; e 17 no sistema público, o que representa $54 \%$ de crescimento neste mesmo período. Entre os graus ou tipos de cursos, 210 eram tecnológicos e 8 bacharelados, sendo a maior concentração de oferta dos cursos tecnológicos no sistema privado, e na oferta de cursos de bacharelado no sistema público com apenas 3 instituições privadas.

Como consequência das diretrizes contidas no Catálogo Nacional dos Cursos Superiores de Tecnologia (MEC, 2016), a formação superior em Gastronomia adota um claro foco na formação de profissionais para o gerenciamento de restaurantes e práticas de cozinha, mas com pouco comprometimento para com a pesquisa científica, como aponta o estudo realizado por Mendes e Faleiros (2013), mesmo que no Parecer CNE/ CES no 438 (Conselho Nacional de Educação [CNE], 2002, p. 2) sobre a educação tecnológica indique que esses cursos são relevantes "para que os cidadãos tenham efetivo acesso às conquistas científicas e tecnológicas da sociedade".

Acredita-se que a questão do desinteresse dos cursos superiores em Gastronomia pela ciência seja resultado da própria construção do conhecimento dessa área. Como a educação formal $\mathrm{da}$ Gastronomia foi introduzida tardiamente, a extradisciplinaridade, ou seja, o conhecimento gerado fora da universidade (Tribe, 1999), foi por muito tempo considerada mais importante para a formação desse profissional em detrimento de outros tipos de conhecimentos, pois até recentemente era o único conhecimento específico na área.

Além disso, como evidenciam Castro, Maciel e Maciel (2016), a Gastronomia por muitas vezes ainda é tratada com desdém por ser associada a algo superficial, pois seu conceito continua engessado em um sentido paradigmático, no contexto do senso comum que a liga somente à estética e aos prazeres da mesa e do comer, fato intimamente relacionado à sua origem no campo literário, posteriormente cultural, pragmático e, por fim, como produto turístico, antes de adquirir qualquer cientificidade ou educação formal (Bueno, 2016). Tal pensamento é corroborado por Haden (2015, p. 494):

1 Disponível em: <http://emec.mec.gov.br/>.
Em termos acadêmicos, a percepção de que qualquer coisa além do estudo científico de alimentos, ou uma compreensão utilitária de cozinhar e jantar, denota uma forma de hedonismo e auto-indulgência, mas também, inversamente, denota algo absolutamente mundano para ser um assunto adequado de pesquisa acadêmica, isso afastou os estudiosos da Gastronomia. ${ }^{2}$

Mas cabe aos estudiosos de Gastronomia e Alimentação reverterem essa situação por meio de um processo de sistematização do conhecimento gerado e de "cientifização" como ocorreu no Turismo (Jafari, 2005): um esforço de presença dos estudos e das pesquisas sobre as temáticas que envolvem o comer e o alimentar-se nos grupos de pesquisas, seminários e congressos científicos, revistas científicas e programas de pós-graduação em âmbito nacional. É possível entender esse processo de "cientifização" a partir da ótica dos Campos de Bourdieu (1976; 1998), como se trata no item a seguir.

\section{GASTRONOMIA SOB A ÓTICA DO CAMPO CIENTÍFICO}

A Teoria dos Campos foi apresentada por Bourdieu após percorrer uma trajetória de reflexão sobre os paradigmas vigentes no século XX nas pesquisas sociais. Bourdieu (1998) realizou críticas à imparcialidade dos pesquisadores com os seus respectivos objetos de pesquisa. Esta crítica permitiu ao autor perceber uma força social invisível que atuava na organização de diversas dimensões do mundo social dos sujeitos de suas pesquisas, denominado por ele como poder simbólico.

Os campos surgiram a partir da associação que o autor fez do poder simbólico como transfiguração de determinados capitais materiais (monetário, alimentos, vestuário, etc.) e não materiais (conhecimento, poder político, etc.) advindos de microcosmos ${ }^{3}$ específicos do mundo

2 "In terms of academic scholarship, the perception that anything other than the scientific study of food, or a utilitarian understanding of cooking and dining, denoted a form of hedonism and self-indulgence, but also, conversely, that food denoted something too absolutely mundane to be a proper subject of academic inquiry, steered scholars away from gastronomy" (Haden, 2015, p. 494).

3 Trata-se de uma concepção sociológica e sistêmica de mundo, a qual, na sua totalidade, pode ser considerada um macrocosmo social composto de macrocosmos sociais (em função de sociedades com suas economias, políticas, culturas, etc.), que, por sua, vez são compostos de microcosmos sociais. Um dos inúmeros microcosmos sociais que compõe um macrocosmo social é o campo de conhecimento (científico) (Fadul et al., 2012). 
social, ou seja, cada microcosmo se tornaria um campo autônomo com capitais específicos imbuídos de poder simbólico. Existem os mais variados tipos de campos, sendo alguns deles o campo da moda, o da religião, o da política, o da literatura, o das artes e o da ciência.

Neste contexto apresentado por Bourdieu (1976), a produção científica também é configurada como um campo, ou seja, possui capitais simbólicos próprios (prestígio, reconhecimento, reputação, conhecimento, etc.) e visa à hegemonia da distribuição desses capitais àqueles que demonstrarem maior competência científica, o que se caracteriza como um jogo ou disputa pela obtenção de poder simbólico.

Para Bourdieu (1976), os agentes buscam a legitimidade para impor uma definição da ciência para cada área de conhecimento. Dessa maneira, não há escolha de referencial, temas, método, publicação e outros constituintes da ciência que não sejam estrategicamente pensados para resultar em maximização de capital simbólico neste campo. Campos científicos tornam-se disciplinas científicas ao adotar uma ordem científica (paradigma) estabelecida pelos agentes dominantes. Ainda sim existem agentes dominados tentando subverter a situação (quebra de paradigma) a todo o momento. Este efeito causa dois resultados: a convergência em temáticas e problemas específicos dentro da disciplina ou campo estruturado; ou, no caso de campos científicos em formação, um interesse de agentes dominados de campos diversos a estudarem objetos desconhecidos de seus campos originais sobre os prismas teóricos dos seus respectivos campos de origem, gerando novas temáticas, métodos, referencial, etc., nos campos em formação.

Sob essa ótica, compreende-se que outras disciplinas e campos científicos mais estruturados apresentam-se analogamente como agentes dessa disputa simbólica pela dominação no campo da Gastronomia. Por ser um campo recente, a Gastronomia tende a receber influências desses agentes que irão contribuir para sua formação. É possível que as disciplinas mantenham lutas simbólicas entre si para determinar um paradigma em um campo segundo seu epistema, também denominado como multidisciplinaridade, mas também unam esforços sobre determinado objeto ou tema para criar uma intersecção entre as disciplinas, denominado como interdisciplinaridade.
Campos científicos, como exemplo do próprio Turismo, há muito tempo se preocupam com a sistematização do conhecimento gerado em seu campo. Autores como Jafari e Ritchie (1981) e Tribe (1997) propuseram modelos, cada qual com sua forma de organizar o conhecimento, que tentassem explicar a influência que as demais áreas ou campos científicos tinham sobre os estudos no campo do Turismo. Tal sistematização ainda não é encontrada no campo da Gastronomia, somente é possível assumir a partir do estudo realizado por GimenesMinasse (2012), que aborda o perfil dos autores e as temáticas de dissertações e teses em Gastronomia produzidas no Brasil, que este campo pode ser caracterizado como multi e interdisciplinar.

\section{METODOLOGIA}

As pesquisas de estado da arte realizam "levantamentos do que se conhece sobre um determinado assunto a partir de pesquisas realizadas em uma determinada área" (Romanowski \& Ens, 2006, p. 41) a partir de dados catalográficos de documentos (título, palavras-chave, instituição, curso, ano, resumo, etc.) para análise temas, subtemas e conteúdos com objetivos de "inventariar e sistematizar a produção em determinada área do conhecimento" (Romanowski \& Ens, 2006, p. 40).

Ferreira (2002) e Romanowski e Ens (2006) organizam o processo metodológico do estado da arte da seguinte maneira: em um primeiro momento, denominado pré-tratamento, há a definição de descritores de busca, a localização de banco de dados, o estabelecimento de critérios de inclusão e exclusão, o levantamento dos documentos; em uma segunda etapa há a interação do pesquisador com os dados catalográficos de maneira quantitativa com o objetivo de mapear a produção científica sobre um assunto e a leitura das publicações; no póstratamento ocorre uma análise qualitativa de leitura e categorização dos dados catalográficos.

Apesar de Ferreira (2002) e Romanowski e Ens (2006) não mencionarem, o tratamento dos dados no método do estado da arte se utiliza das técnicas de análise de conteúdo de Bardin (2011). A análise de conteúdo dá suporte ao estado da arte na definição das unidades de registro (UR) e de contexto (UC), neste caso os dados catalográficos e os resumos, para posterior categorização e alocação desses UR e UC, sistematizando informações para facilitar análises tanto qualitativas quanto quantitativas. 
O estado da arte é considerado o método norteador dessa pesquisa, por conta dos seus objetivos de aplicação, e a análise de conteúdo o procedimento metodológico adotado como principal ferramenta para o tratamento dos dados levantados.

O termo de busca "Gastronomia" foi aplicado no banco de dissertações e teses da CAPES, por esta base reunir todos os registros de pesquisas acadêmicas geradas em programas de pósgraduação stricto sensu recomendados no Brasil, com um recorte entre os anos de 1999 e 2016.

A busca respondeu com 342 documentos até a data de 31 de maio de 2017. Em seguida, adotou-se como critério de inclusão/exclusão a abordagem direta e indireta com o campo da Gastronomia definida a partir da leitura do título e palavras-chave de cada documento. Quando essas informações não eram suficientes, efetuouse uma leitura do resumo e da introdução. Antes da definição da amostra final, checaram-se novamente os documentos para evitar possíveis exclusões ou inclusões equivocadas. Ao final do processo, estabeleceu-se uma amostra final de 223 documentos.

Dos dados catalográficos se extraíram e se categorizaram as seguintes UR: a) palavraschave; b) tipo de documento (dissertação ou tese); c) origem/instituição/faculdade; d) nome do programa; e) ano de defesa; f) região. Os resultados dessa etapa a priori permitiram o mapeamento da produção científica desse campo de maneira quantitativa.

A partir da leitura e da análise qualitativa do UC Resumo e da UR Título, foi possível categorizar, a posteriori, o conteúdo dos documentos em 19 categorias temáticas. Essas temáticas foram submetidas novamente à análise, confrontando-as com as informações das demais categorias geradas a priori.

Para permitir a elaboração de um modelo de abordagens temáticas baseado nas dissertações e nas teses sobre Gastronomia, foi necessário reclassificar as categorias temáticas criadas a posteriori, resultando em 12 novas categoriais para depois agrupá-las, segundo suas afinidades, em 3 abordagens: comercial, não comercial e de saúde.

\section{GASTRONOMIA NO CENÁRIO DA PESQUISA CIENTÍFICA BRASILEIRA}

\section{CARACTERIZAÇÃO GERAL}

A amostra da pesquisa foi composta majoritariamente por dissertações de mestrado, cerca de $87 \%$. A distribuição anual dessas pesquisas apresentou crescimento irregular. A amostra não possui documentos nos anos de 2000 e 2002, mas demonstrou ápices de produção nos anos de 2003, 2006, 2012 e 2015. O período entre 2006 e 2016 possui produção média de 18 documentos ao ano, sendo 2015 com 37 documentos (Figura 1).

O início da produção científica no campo da Gastronomia se iniciou em paralelo com o início da oferta dos cursos superiores de Gastronomia no Brasil, em 1999 (Sogayar \& Rejowski, 2014). É interessante observar também que há uma relação entre o crescimento da produção científica e a oferta de cursos superiores no campo da Gastronomia (e-MEC, 2018). Como apontado por Miyazaki (2006), o interesse pela produção científica neste campo também pode ser consequência da exigência do MEC quanto às titulações de professores para educação superior.

Dentre as regiões mais prolíficas, destacase a região Sudeste com 105 documentos, logo em seguida a região Sul (56) e Nordeste (41). As regiões Centro-Oeste e Norte apresentam as menores quantidades de documentos, 16 e 6 documentos, respectivamente. As regiões Nordeste, Sul e Sudeste apresentaram um fluxo quase contínuo de produção científica. Não houve produção na região Sudeste nos anos de 2001 e 2004, enquanto que o Nordeste, em 2004, também não apresentou documentos. Já a região Sul apresentou fluidez na produção de documentos desde o início do período.

As dissertações e as teses foram produzidas em 76 diferentes instituições de ensino, tanto privadas (53\%) quanto públicas (47\%). A maioria dessa produção concentrou-se em 5 instituições: Universidade do Vale do Itajaí - UNIVALI (24), Universidade Anhembi Morumbi - UAM (24), Pontifícia Universidade Católica de São Paulo PUC-SP (13), Universidade de São Paulo - USP (12) e Universidade Federal de Pernambuco UFPE (10). 
Figura 1 - Evolução temporal da amostra por instituição de ensino

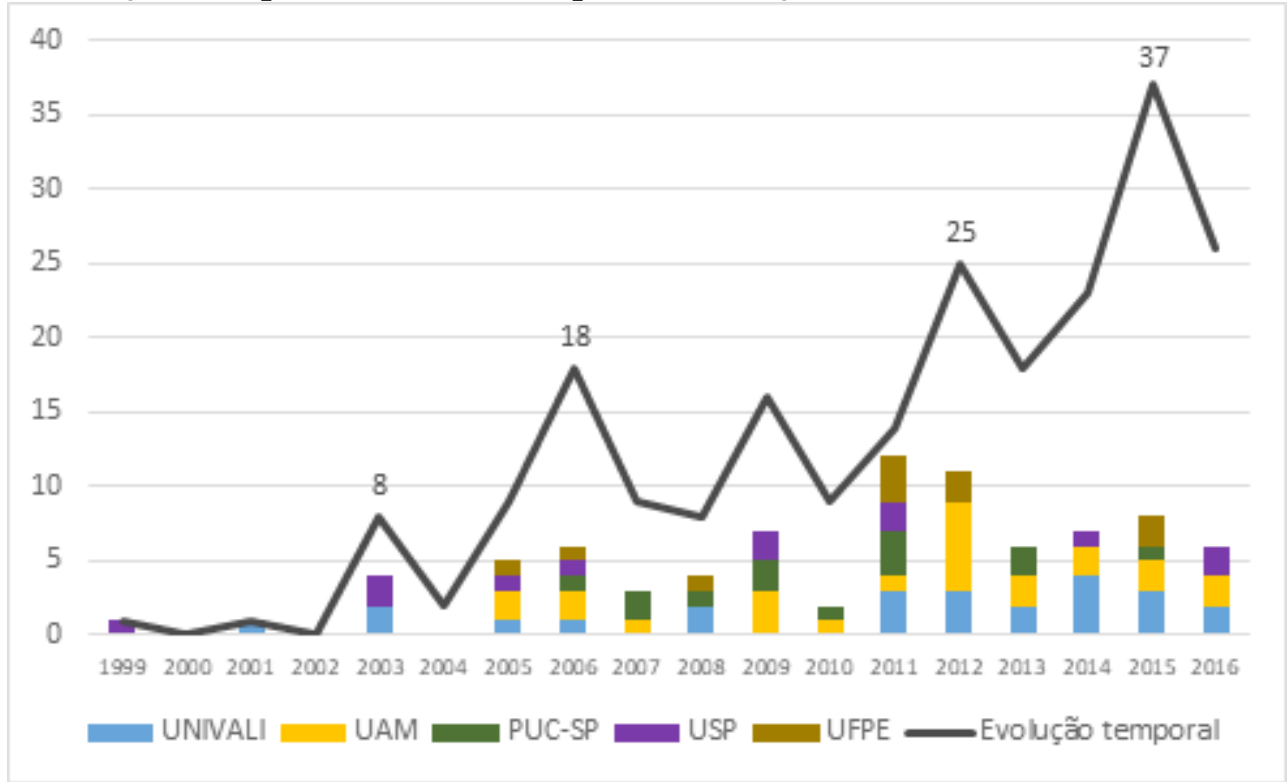

Fonte: Elaboração dos autores (2017).

A maior concentração das pesquisas na UNIVALI e na UAM pode se relacionar ao fato de que estas universidades têm cursos de graduação em Gastronomia referenciais no país e também ofertam mestrados e doutorados em Turismo e Hospitalidade no período, respectivamente, cujo estudo da Gastronomia teve maior presença do que em programas de outras áreas.

A primeira pesquisa sobre Gastronomia foi produzida em 1999 na USP, considerada, então, instituição pioneira neste campo. Após a USP, a UNIVALI iniciou uma produção intermitente a partir de 2001. Já a UAM iniciou sua produção em 2005, que seguiu mais constante até 2016, com apenas 1 ano sem nenhuma produção (2008). Com auxílio da Figura 1, é possível notar que os estudos desse campo estão dispersos e ganharam espaço em outras instituições.

Figura 2 - Grandes áreas do conhecimento da amostra

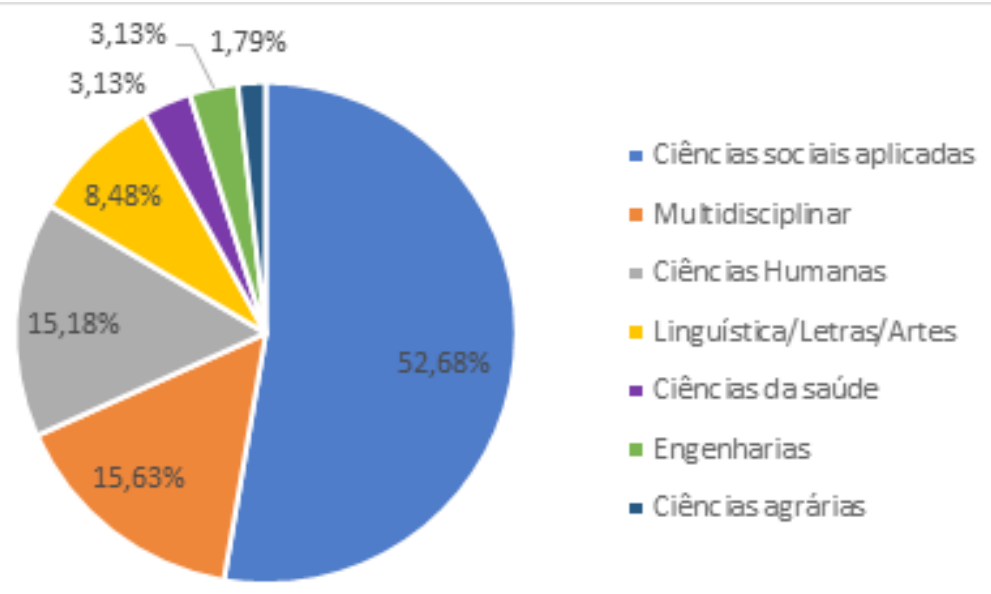

Fonte: elaboração dos autores (2017).

Os documentos da amostra distribuem-se por 7 grandes áreas, sendo a Ciências Sociais Aplicadas a mais significativa. Subsequentemente duas outras se destacam, Multidisciplinar e Ciências Humanas. As demais, Linguística/Letras/Artes,
Ciências da Saúde, Engenharia e Ciência Agrárias possuem pouca representatividade (Figura 2). As únicas grandes áreas sem pesquisas sobre Gastronomia são Ciências Biológicas e Ciências Exatas e da Terra (Figura 2). 
Algumas áreas se esperava maior presença na amostra dessa pesquisa, principalmente aquelas relacionadas com os estudos agrários e rurais, como Extensão Rural, Ciência dos Alimentos, Agronomia e Geografia, por compor parte dos sistemas alimentares (Poulain, 2002). É necessário ressaltar, porém, que o termo de busca utilizado nesta pesquisa ("Gastronomia") pode ser interpretado como pejorativo ou associado somente aos serviços de alimentação, sem conotações culturais e afinidade com a produção dos alimentos. Neste caso, possivelmente, o termo Alimentação, por exemplo, poderá ser um termo mais aceito e utilizado nestas áreas, assim como nas áreas da Saúde.

\section{ANÁLISE TEMÁTICA}

Inicialmente, registraram-se 504 palavraschave, que, excluídas variações de plural, chegouse ao total de 466, com destaque para a Gastronomia (108), valor compreensível pelo termo de busca utilizado para extrair os documentos, seguida de Turismo (28), Restauração (20), Cultura (18), Alimentação (12), Identidade (9), Culinária (8), Formação profissional e Chefe de Cozinha (ambos 7), Desenvolvimento local, Imigração e Comunicação (6), Cozinha, Resíduos sólidos e Patrimônio cultural (5 cada um). Outros termos restantes possuíam quatro ocorrências ou menos.

Realizou-se também uma categorização das palavras-chave conforme suas proximidades temáticas. Obtiveram-se 35 categorias temáticas, com destaque para as que possuíam maiores frequências: Gastronomia (131), Educação e Qualificação (55), Turismo (51), Comunicação (48), Cultura, Memória e Simbolismos (42), Administração, Economia, Mercado e Estratégia (37), Locais de estudo (36), Serviços de Alimentação e Nutrição (35), Patrimônio e Identidade (28), Arte, Estética e Experiência (27) e Literatura e Linguística (25).

Em síntese, é possível presumir que as pesquisas em Gastronomia no Brasil são voltadas aos estudos das diversas culturas presentes no país, suas linguagens, identidades, memórias e saberfazer relacionados à Gastronomia. Também é possível incluir estudos de mediação e midiatização que abarcam a semiótica dessas culturas em diversos meios de comunicação; e ainda Turismo e Eventos juntamente com a Oferta gastronômica (Gestão de alimentos e bebidas/restauração) como propulsores de desenvolvimento local. A Educação é outra categoria que merece atenção, pois se preocupa com a qualidade do ensino, do currículo e da formação profissional na área da Gastronomia. Por fim, propõe-se um olhar às outras categorias como a Estetização e a "Artificação" da Gastronomia e a Sustentabilidade Ambiental como tendências para o campo.

Com o auxílio das UR Objetivo e Objeto contidas na UC Resumo e da UR Título, foi possível classificar o conteúdo dos documentos em 19 categorias temáticas elencadas no Quadro 1.

Quadro 1 - Frequência e síntese teórica das temáticas e subtemáticas das dissertações e das teses em Gastronomia (1999-2016)

\begin{tabular}{|c|c|c|c|}
\hline Temática & $\begin{array}{c}\text { Freq. } \\
(\mathbf{n} .)\end{array}$ & $\%$ & Síntese teórica \\
\hline $\begin{array}{l}\text { Identidade e } \\
\text { Patrimônio }\end{array}$ & 35 & $15,70 \%$ & $\begin{array}{c}\text { Pesquisas voltadas à inventariação e à caracterização de cozinhas típicas } \\
\text { segundo seus atores, normalmente migrantes/imigrantes, e o poder } \\
\text { de identidade que essas cozinhas possuem para estes indivíduos. Estes } \\
\text { estudos também abordam a gastronomia étnica como Patrimônio } \\
\text { e como símbolo de acolhimento, que muitas vezes também são } \\
\text { aproveitados pelo turismo, gerando desenvolvimento do local. São } \\
\text { objetos dessas pesquisas os próprios imigrantes e os restaurantes } \\
\text { étnicos. }\end{array}$ \\
\hline $\begin{array}{l}\text { Ensino em } \\
\text { gastronomia }\end{array}$ & 32 & $14,35 \%$ & $\begin{array}{l}\text { Ensino da gastronomia em nível técnico, livre e superior. Há } \\
\text { preocupação com a formulação do currículo, com as tecnologias e as } \\
\text { metodologias de ensino aliadas à sustentabilidade e às competências } \\
\text { técnicas. Estudos com todos os atores representativos do espaço } \\
\text { curricular. O ensino em gastronomia também foi caracterizado como } \\
\text { inclusão social. }\end{array}$ \\
\hline $\begin{array}{l}\text { Administração } \\
\text { de alimentos e } \\
\text { bebidas }\end{array}$ & 27 & $12,11 \%$ & $\begin{array}{l}\text { Trata da gestão de serviços de alimentação. Estudos financeiros, de } \\
\text { recursos humanos, de processos e controles operacionais, estratégias de } \\
\text { marketing e, por fim, da gestão da experiência de consumo. }\end{array}$ \\
\hline
\end{tabular}




\begin{tabular}{|c|c|c|c|}
\hline $\begin{array}{l}\text { Gastronomia } \\
\text { como atrativo }\end{array}$ & 20 & $8,97 \%$ & $\begin{array}{l}\text { A ótica é voltada à demanda turística e sua percepção sobre o setor ou } \\
\text { as manifestações gastronômicas que influenciam no turismo local. Para } \\
\text { tanto são realizados estudos em restaurantes, em receitas, etnográficos } \\
\text { para se caracterizar as cozinhas típicas, com fins de Patrimônio ou não, } \\
\text { com auxílio dos turistas e da população local que detém o saber-fazer. }\end{array}$ \\
\hline $\begin{array}{l}\text { Alimentação } \\
\text { nos Meios de } \\
\text { comunicação }\end{array}$ & 22 & $9,87 \%$ & $\begin{array}{l}\text { Esta temática contempla estudos semióticos da gastronomia em objetos } \\
\text { da área de comunicação social: fotografia, televisão, rádio, mídias } \\
\text { impressas e digitais. As temáticas buscam entender como é o processo } \\
\text { de mediação e midiatização do fenômeno gastronômico nesses veículos, } \\
\text { a representação de gêneros e étnica das cozinhas comunicadas. }\end{array}$ \\
\hline $\begin{array}{l}\text { Oferta } \\
\text { gastronômica }\end{array}$ & 16 & $7,17 \%$ & $\begin{array}{l}\text { Os serviços de Alimentação são estudados aqui pela ótica da oferta. } \\
\text { Preocupa com a caracterização e a comprovação étnica/tipicidade das } \\
\text { cozinhas ofertadas, de tipologias e qualidade de restaurantes. A análise } \\
\text { nutricional da oferta, dos ingredientes e das técnicas aplicados nos } \\
\text { cardápios e Sustentabilidade ambiental são temas com recorrência e } \\
\text { auxiliam na caracterização de empreendimentos. }\end{array}$ \\
\hline $\begin{array}{l}\text { Locais de } \\
\text { manifestações } \\
\text { gastronômicas }\end{array}$ & 15 & $6,73 \%$ & $\begin{array}{c}\text { Estudos que apresentam outros tipos e locais passíveis de manifestação } \\
\text { do fenômeno gastronômico e o poder de desenvolvimento local que } \\
\text { esses locais possuem. }\end{array}$ \\
\hline $\begin{array}{l}\text { Linguagem } \\
\text { e literatura } \\
\text { gastronômica }\end{array}$ & 14 & $6,28 \%$ & $\begin{array}{c}\text { Pesquisas envolvendo os aspectos de diversas linguagens étnicas em } \\
\text { cardápios de restaurantes no Brasil, livros de nacionalidades distintas e } \\
\text { falas de grupos sociais. }\end{array}$ \\
\hline Ingredientes & 9 & $4,04 \%$ & $\begin{array}{l}\text { Estudos socioeconômicos de ingredientes e de aplicabilidade no } \\
\text { mercado gastronômico. Em outros casos os ingredientes são vistos } \\
\text { como Patrimônio e se tornam atrativo turístico. }\end{array}$ \\
\hline $\begin{array}{l}\text { Boas práticas } \\
\text { em serviços de } \\
\text { alimentação }\end{array}$ & 8 & $3,59 \%$ & $\begin{array}{l}\text { Estudos voltados à gestão de processos em segurança alimentar e } \\
\text { sustentabilidade nos serviços de alimentação. }\end{array}$ \\
\hline $\begin{array}{l}\text { Conglomerados } \\
\text { turísticos- } \\
\text { gastronômicos }\end{array}$ & 5 & $2,24 \%$ & $\begin{array}{l}\text { Os conglomerados são considerados pelos autores como vetores de } \\
\text { desenvolvimento local. }\end{array}$ \\
\hline $\begin{array}{l}\text { Artificação e } \\
\text { estetização }\end{array}$ & 5 & $2,24 \%$ & $\begin{array}{l}\text { São estudos sobre a percepção social da comida como arte e } \\
\text { sensorialidade por meio de espetáculos cênicos ou apresentação de } \\
\text { pratos. }\end{array}$ \\
\hline $\begin{array}{l}\text { Sociologia da } \\
\text { alimentação }\end{array}$ & 4 & $1,79 \%$ & $\begin{array}{l}\text { A sociologia se preocupou em compreender como a gastronomia pode } \\
\text { ser um fator de diferenciação social. Além de estudar os movimentos } \\
\text { gastronômicos pelo ponto de vista dos movimentos sociais. }\end{array}$ \\
\hline $\begin{array}{l}\text { Ciência e } \\
\text { tecnologia de } \\
\text { alimentos }\end{array}$ & 3 & $1,35 \%$ & $\begin{array}{l}\text { Melhoramento nutricional de receitas e ingredientes com auxílio de } \\
\text { tecnologia ou ciência. }\end{array}$ \\
\hline $\begin{array}{l}\text { História da } \\
\text { alimentação }\end{array}$ & 3 & $1,35 \%$ & $\begin{array}{l}\text { A história da alimentação se preocupa com o conhecimento de aspectos } \\
\text { culinários de determinada época e com a hibridização cultural que } \\
\text { ocorreu ao longo da construção histórica de uma cozinha. }\end{array}$ \\
\hline $\begin{array}{l}\text { Filosofia da } \\
\text { gastronomia }\end{array}$ & 2 & $0,90 \%$ & $\begin{array}{l}\text { Estudos que tratam da bioética na gastronomia e da afetividade } \\
\text { relacionada às refeições, como o comfort food. }\end{array}$ \\
\hline $\begin{array}{l}\text { Gastronomia e } \\
\text { religião }\end{array}$ & 1 & $0,45 \%$ & $\begin{array}{l}\text { Expressões religiosas circunscritas em determinados territórios } \\
\text { possuem expressões gastronômicas próprias. }\end{array}$ \\
\hline $\begin{array}{l}\text { Política e } \\
\text { Gastronomia }\end{array}$ & 1 & $0,45 \%$ & $\begin{array}{c}\text { Gastronomia nesta temática é tratada como símbolo de diplomacia } \\
\text { perante tratados e relações internacionais. }\end{array}$ \\
\hline $\begin{array}{l}\text { Psicologia } \\
\text { alimentar }\end{array}$ & 1 & $0,45 \%$ & $\begin{array}{l}\text { e restringiu a estudo sobre transtornos } \\
\text { ociados ao ato de se alimentar. }\end{array}$ \\
\hline
\end{tabular}

Fonte: elaborado pelos autores (2017). 
Destacam-se as temáticas mais relevantes segundo a frequência de documentos, ou seja: Identidade e Patrimônio (35), Educação (32), Administração de Alimentos e Bebidas (27), Alimentação nos Meios de Comunicação (22), Gastronomia como Atrativo turístico (20), Oferta gastronômica (16), Locais de manifestações gastronômicas (15), Linguagem e Literatura gastronômica (14). As demais temáticas possuem menos de dez documentos em sua categorização.

Foi possível observar que nenhuma temática possui fluxo contínuo de produção, mas algumas, como Administração de alimentos e bebidas, Ensino em Gastronomia, Identidade e patrimônio, Oferta gastronômica e Alimentação nos meios de comunicação, possuem concentração de documentos em anos esporádicos.

Com relação ao surgimento das temáticas conforme os anos, há inserção de novas temáticas no campo da Gastronomia continuamente entre 1999 e 2008. Em todos os anos deste período apareceu uma ou mais novas temáticas sobre a Gastronomia, com ênfase em 2003, com 6 temáticas. Entre 2009 e 2011 nenhuma nova temática foi proposta. Após este período as temáticas Filosofia da Alimentação, Gastronomia e política e, por fim, Gastronomia e religião, foram inseridas no campo.

O efeito de inserção de novas temáticas em um campo foi anteriormente apontado por Bourdieu (1976), em que é possível ocorrer a convergência de temáticas e problemas específicos dentro de um campo científico em formação até certo ponto cujos novos agentes se interessaram por objetos desconhecidos fora dos seus campos originais, resultando em novas temáticas, métodos, referencial, etc. nos campos em formação.

Outro fato que pode contribuir para o domínio epistemológiconocampoda Gastronomia sob a tutela de determinados campos mais estruturados, áreas ou disciplinas, é a condições institucionalizada dos programas de pós-graduação stricto sensu. Os cursos de mestrado e doutorado devem seguir determinadas linhas de conhecimento preexistentes alocadas nas áreas de conhecimento da CAPES. Os professoresorientadores e os alunos, consequentemente, também precisam adequar os seus projetos de pesquisa segundo a linha seguida pelo programa. Isso impede o aumento da produção científica no campo da Gastronomia em determinadas áreas com paradigmas muito enraizados. No sentido contrário, há professores-orientadores se apropriando do conhecimento do programa no qual está alocado e aplicando em pesquisas com temáticas voltadas à Gastronomia e à Alimentação. Este fato oportuniza alunos interessados em prosseguir com os estudos em sua área de formação (para graduados em Gastronomia) ou alunos de outras áreas que se interessam por Gastronomia e Alimentação.

Em relação às áreas, destacam-se o Turismo e a Interdisciplinar como as mais presentes na amostra, seguida de Administração (18 documentos), Comunicação (18), Educação (13) e Letras (12). Também é possível notar que, apesar da pouca relevância da Gastronomia em algumas áreas, a produção científica nesse campo está presente em 27 diferentes áreas do conhecimento (Tabela 1).

A Tabela 1 apresenta as afinidades temáticas de cada área que compuseram a amostra. Observase que a maioria das áreas possuem temáticas definidas no campo da Gastronomia, como é o caso da Administração, Artes, Comunicação, Educação, História, Letras, Linguística, Nutrição e Planejamento Urbano e Regional. Outras áreas, por sua natureza interdisciplinar, recente formação como área ou pouca participação na amostra, impossibilitam a definição de uma predileção temática. Turismo é um caso em destaque, pois concentra 8 temáticas diferentes neste campo.

Tabela 1 - Temas e frequência por área nas dissertações e das teses sobre Gastronomia (1999-2016)

\begin{tabular}{cccc}
\hline Área & Temática & Freq. (n.) & $\%$ \\
& Identidade e Patrimônio & 15 & $22,39 \%$ \\
Gastronomia como atrativo & 12 & $17,91 \%$ \\
Ensino em gastronomia & 12 & $17,91 \%$ \\
\multirow{3}{*}{ Turismo } & Análise da oferta gastronômica & 10 & $14,93 \%$ \\
& Administração de alimentos e bebidas & 8 & $11,94 \%$ \\
& Locais de manifestações gastronômicas & 6 & $8,96 \%$ \\
Alimentação nos Meios de comunicação & 3 & $4,48 \%$ \\
Ingredientes & 1 & $1,49 \%$ \\
\hline
\end{tabular}




\begin{tabular}{|c|c|c|c|}
\hline \multirow{11}{*}{$\begin{array}{l}\text { Interdisciplinar } \\
\text { (Engenharia/ } \\
\text { Tecnologia/ } \\
\text { Gestão; Meio } \\
\text { Ambiente e } \\
\text { Agrárias; Saúde } \\
\text { e Biológicas; } \\
\text { Sociais e } \\
\text { Humanidades) }\end{array}$} & & 67 & $30,04 \%$ \\
\hline & Ensino em gastronomia & 6 & $20,69 \%$ \\
\hline & Identidade e Patrimônio & 5 & $17,24 \%$ \\
\hline & Ingredientes & 4 & $13,79 \%$ \\
\hline & Gastronomia como atrativo & 3 & $10,34 \%$ \\
\hline & Locais de manifestações gastronômicas & 3 & $10,34 \%$ \\
\hline & Boas práticas em serviços de alimentação & 3 & $10,34 \%$ \\
\hline & Alimentação nos Meios de comunicação & 2 & $6,90 \%$ \\
\hline & Análise da oferta gastronômica & 1 & $3,45 \%$ \\
\hline & História da alimentação & 1 & $3,45 \%$ \\
\hline & Filosofia da gastronomia & 1 & $3,45 \%$ \\
\hline \multirow{4}{*}{ Comunicação } & & 29 & $13,00 \%$ \\
\hline & Alimentação nos Meios de comunicação & 16 & $88,89 \%$ \\
\hline & Filosofia da gastronomia & 1 & $5,56 \%$ \\
\hline & Identidade e Patrimônio & 1 & $5,56 \%$ \\
\hline \multirow{8}{*}{ Administração } & & 18 & $8,07 \%$ \\
\hline & Administração de alimentos e bebidas & 10 & $55,56 \%$ \\
\hline & Locais de manifestações gastronômicas & 2 & $11,11 \%$ \\
\hline & Ensino em gastronomia & 2 & $11,11 \%$ \\
\hline & Conglomerados turísticos-gastronômicos & 1 & $5,56 \%$ \\
\hline & Sociologia da alimentação & 1 & $5,56 \%$ \\
\hline & Gastronomia como atrativo & 1 & $5,56 \%$ \\
\hline & Análise da oferta gastronômica & 1 & $5,56 \%$ \\
\hline \multirow{4}{*}{ Educação } & & 18 & $8,07 \%$ \\
\hline & Ensino em gastronomia & 11 & $84,62 \%$ \\
\hline & Alimentação nos Meios de comunicação & 1 & $7,69 \%$ \\
\hline & Identidade e Patrimônio & 1 & $7,69 \%$ \\
\hline \multirow{4}{*}{ Letras } & & 13 & $5,83 \%$ \\
\hline & Linguagem e literatura gastronômica & 10 & $83,33 \%$ \\
\hline & Gastronomia como atrativo & 1 & $8,33 \%$ \\
\hline & Identidade e Patrimônio & 1 & $8,33 \%$ \\
\hline \multirow{5}{*}{ Sociologia } & & 12 & $5,38 \%$ \\
\hline & Artificação e Estetização & 2 & $25,00 \%$ \\
\hline & Identidade e Patrimônio & 2 & $25,00 \%$ \\
\hline & Locais de manifestações gastronômicas & 2 & $25,00 \%$ \\
\hline & Sociologia da alimentação & 2 & $25,00 \%$ \\
\hline \multirow{4}{*}{$\begin{array}{l}\text { Planej. Urbano } \\
\text { e Regional }\end{array}$} & & 8 & $3,59 \%$ \\
\hline & Conglomerados turísticos-gastronômicos & 4 & $57,14 \%$ \\
\hline & Identidade e Patrimônio & 2 & $28,57 \%$ \\
\hline & Gastronomia local como atrativo turístico & 1 & $14,29 \%$ \\
\hline \multirow{4}{*}{ Nutrição } & & 7 & $3,14 \%$ \\
\hline & Boas práticas em serviços de alimentação & 3 & $50,00 \%$ \\
\hline & Ciência e tecnologia de alimentos & 2 & $33,33 \%$ \\
\hline & Análise da oferta gastronômica & 1 & $16,67 \%$ \\
\hline
\end{tabular}




\begin{tabular}{|c|c|c|c|}
\hline \multirow{2}{*}{ História } & Identidade e Patrimônio & 4 & $80,00 \%$ \\
\hline & História da alimentação & 1 & $20,00 \%$ \\
\hline \multirow{5}{*}{$\begin{array}{l}\text { Engenharia de } \\
\text { produção }\end{array}$} & & 5 & $2,24 \%$ \\
\hline & Administração de alimentos e bebidas & 2 & $40,00 \%$ \\
\hline & Boas práticas em serviços de alimentação & 1 & $20,00 \%$ \\
\hline & Conglomerados turísticos-gastronômicos & 1 & $20,00 \%$ \\
\hline & Locais de manifestações gastronômicas & 1 & $20,00 \%$ \\
\hline \multirow{5}{*}{$\begin{array}{l}\text { Ciências } \\
\text { ambientais }\end{array}$} & & 5 & $2,24 \%$ \\
\hline & Ingredientes & 2 & $40,00 \%$ \\
\hline & Boas práticas em serviços de alimentação & 1 & $20,00 \%$ \\
\hline & Gastronomia como atrativo & 1 & $20,00 \%$ \\
\hline & Análise da oferta gastronômica & 1 & $20,00 \%$ \\
\hline \multirow{3}{*}{ Linguística } & & 5 & $2,24 \%$ \\
\hline & Linguagem e literatura gastronômica & 4 & $100,00 \%$ \\
\hline & & 4 & $1,79 \%$ \\
\hline \multirow{3}{*}{ Arquitetura } & Administração de alimentos e bebidas & 1 & $33,33 \%$ \\
\hline & Ensino em gastronomia & 1 & $33,33 \%$ \\
\hline & Identidade e Patrimônio & 1 & $33,33 \%$ \\
\hline \multirow{4}{*}{ Geografia } & & 3 & $1,35 \%$ \\
\hline & Gastronomia local como atrativo turístico & 1 & $33,33 \%$ \\
\hline & Identidade e Patrimônio & 1 & $33,33 \%$ \\
\hline & Gastronomia e território & 1 & $33,33 \%$ \\
\hline \multirow{3}{*}{ Artes } & & 3 & $1,35 \%$ \\
\hline & Artificação e Estetização & 3 & $100,00 \%$ \\
\hline & & 3 & $1,35 \%$ \\
\hline \multirow[t]{2}{*}{$\begin{array}{l}\text { Desenho } \\
\text { industrial }\end{array}$} & Administração de alimentos e bebidas & 2 & $100,00 \%$ \\
\hline & & 2 & $0,90 \%$ \\
\hline \multirow{2}{*}{$\begin{array}{c}\text { Ciência e } \\
\text { tecnologia dos } \\
\text { alimentos }\end{array}$} & Análise da oferta gastronômica & 1 & $50,00 \%$ \\
\hline & Ingredientes & 1 & $50,00 \%$ \\
\hline \multirow{3}{*}{ Ciência política } & & 2 & $0,90 \%$ \\
\hline & Identidade e Patrimônio & 1 & $50,00 \%$ \\
\hline & Política e Gastronomia & 1 & $50,00 \%$ \\
\hline \multirow{3}{*}{ Antropologia } & & 2 & $0,90 \%$ \\
\hline & Identidade e Patrimônio & 1 & $50,00 \%$ \\
\hline & Sociologia da alimentação & 1 & $50,00 \%$ \\
\hline \multirow{3}{*}{ Extensão rural } & & 2 & $0,90 \%$ \\
\hline & Locais de manifestações gastronômicas & 1 & $50,00 \%$ \\
\hline & História da alimentação & 1 & $50,00 \%$ \\
\hline \multirow{3}{*}{ Economia } & & 2 & $0,90 \%$ \\
\hline & Administração de alimentos e bebidas & 1 & $100,00 \%$ \\
\hline & & 1 & $0,45 \%$ \\
\hline \multirow[t]{2}{*}{$\begin{array}{l}\text { Engenharia } \\
\text { sanitária }\end{array}$} & Ensino em gastronomia & 1 & $100,00 \%$ \\
\hline & & 1 & $0,45 \%$ \\
\hline
\end{tabular}




\begin{tabular}{|c|c|c|c|}
\hline Medicina & Análise da oferta gastronômica & 1 & $100,00 \%$ \\
\hline & & 1 & $0,45 \%$ \\
\hline $\begin{array}{l}\text { Engenharia } \\
\text { Química }\end{array}$ & Ciência e tecnologia de alimentos e necessidades nutricionais & 1 & $100,00 \%$ \\
\hline & & 1 & $0,45 \%$ \\
\hline \multirow[t]{2}{*}{ Psicologia } & Psicologia alimentar & 1 & $100,00 \%$ \\
\hline & & 1 & $0,45 \%$ \\
\hline \multirow[t]{2}{*}{ Serviço social } & Ingredientes & 1 & $100,00 \%$ \\
\hline & & 1 & $0,45 \%$ \\
\hline Total & & 223 & $100,00 \%$ \\
\hline
\end{tabular}

Fonte: elaborado pelos autores (2017).

Vale ressaltar que a estreita relação entre a Gastronomia e seus campos originários, Letras, Comunicação, Administração e Turismo (Bueno, 2016), vigora até os dias de hoje, sendo algumas das áreas mais relevantes desse campo.

Constatou-se que há uma sobreposição de temáticas quanto às disciplinas que as produzem, mesmo com predileções temáticas por parte de algumas delas. As regiões possuem uma identidade científica diante do campo da Gastronomia que pode ser observada ao analisar as incidências das temáticas produzidas em cada uma. É importante reparar que, apesar de a Gastronomia ser um campo científico novo, as temáticas são reincidentes e novas abordagens escasseiam desde 2008 .

Estes fatos podem indicar que as temáticas e os objetos de estudos já se encontram em estado de predefinição neste campo a partir de alguns atores (disciplinas/campos) que possuem maior influência, mesmo com novos entrantes esporádicos. Desta maneira, seria possível propor uma configuração científica deste campo.

\section{CONFIGURAÇÃO PRELIMINAR DO CAMPO DE ESTUDO E PESQUISA}

Para desenvolver o modelo teórico, realizouse uma nova categorização das temáticas (Quadro 2), desta vez diante de seus aspectos e abordagens, agrupando-as em 12 novas categorias, como mostrado no Quadro 2. Algumas temáticas, por possuírem estudos de aspectos mistos, foram repetidas em ambos os aspectos, a saber: Locais de manifestações gastronômicas, Gastronomia como atrativo, Ingredientes, Ciência e tecnologia de alimentos e Boas práticas em serviços de Alimentação.

Quadro 2 - Recategorização das temáticas das dissertações e das teses sobre Gastronomia segundo seus aspectos e abordagens

\begin{tabular}{|c|c|c|}
\hline Aspectos & Temáticas contempladas & Abordagem \\
\hline & Administração de alimentos e bebidas & \\
& Oferta gastronômica & \\
Econômicos & Conglomerados turísticos-gastronômicos & \\
& Ingredientes & \\
& Locais de manifestações gastronômicas & Gastronomia como atrativo \\
\hline Tecnológicos & Ciência e tecnologia de alimentos & \\
\hline Políticos & Gastronomia e política & \\
\hline Ambientais & Boas práticas em serviços de Alimentação & \\
\hline
\end{tabular}




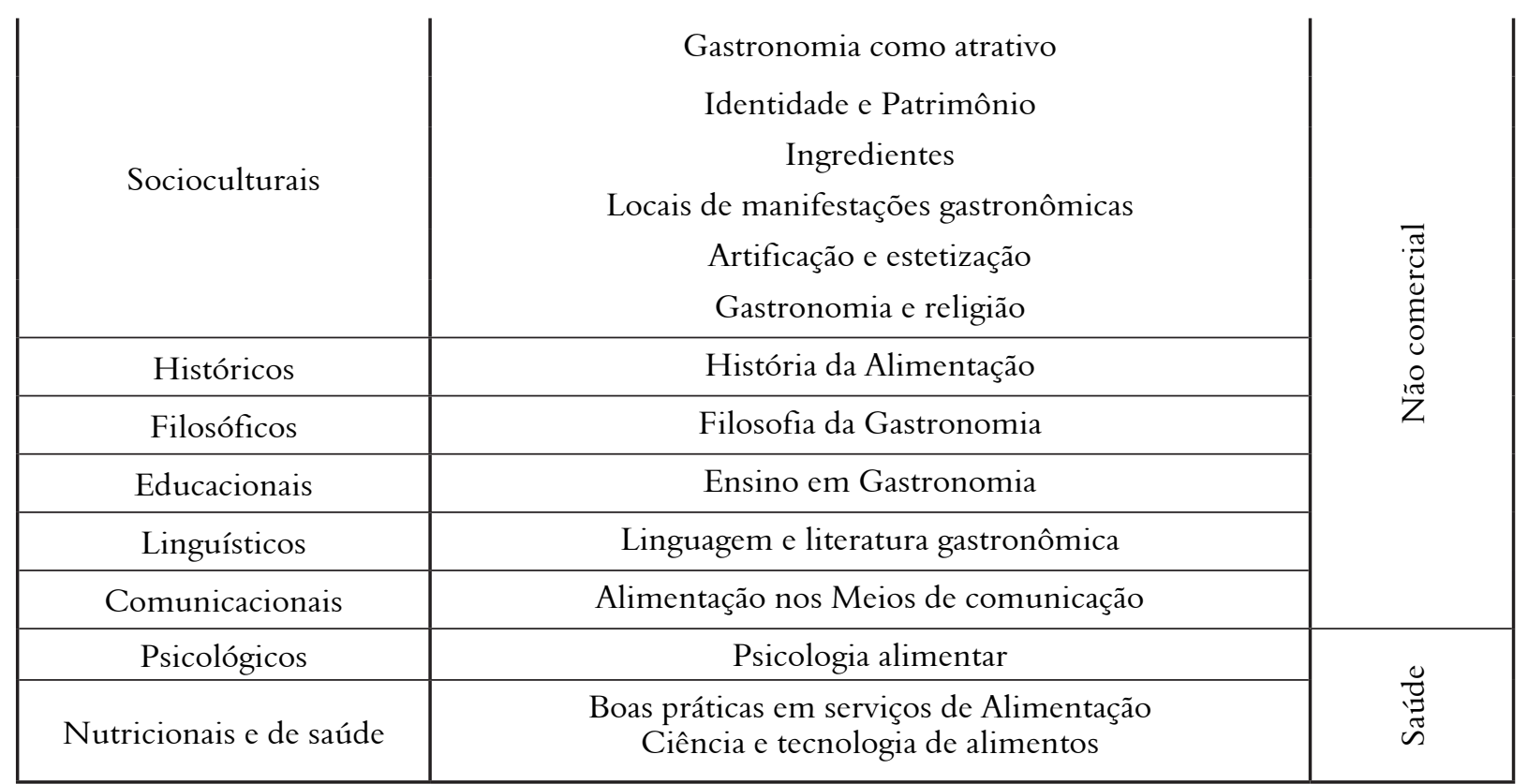

Fonte: elaborado pelos autores (2017).

Desse modo, é possível entender que o campo da Gastronomia possui basicamente três abordagens: comercial, não comercial e de saúde.

A abordagem comercial se preocupa em discutir os aspectos econômicos, de abastecimento, aquisição, consumo de ingredientes ou serviços de alimentação, de gestão e de configuração espacial, políticos, ambientais e sustentáveis de eventos, e empresas públicas e privadas para fins turísticos ou não. $\mathrm{O}$ aspecto tecnológico é atribuído aos estudos sobre ciência e tecnologia de ingredientes para aplicação no mercado.

Enquanto na abordagem não comercial são produzidos estudos sobre aspectos humanos e sociais de identidade e história, podendo estes serem explorados pelo turismo por meio de eventos e comunidades étnicas, outros estudos se interessam pela filosofia, ensino, linguagem e comunicação da Gastronomia. Também se destacam as interpretações artísticas e estéticas da alimentação, as perspectivas culturais de ingredientes e discussões sobre as religiões e sua influência na Gastronomia.

Por fim, os estudos que abordam a saúde implicam a manutenção da inocuidade e da psique alimentar, e os estudos sobre a ciência e tecnologia de alimentos em prol da nutrição humana.

O modelo apresentado na Figura 3 esquematiza as informações do Quadro 2 diante dos aspectos e das abordagens encontradas nas dissertações e nas teses produzidas no campo da Gastronomia.

Figura 3 - Configuração preliminar do campo da Gastronomia no Brasil

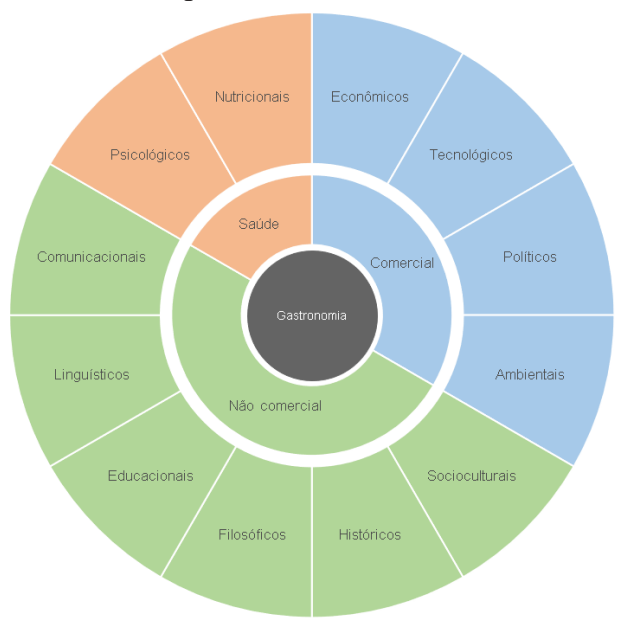

Fonte: elaborada pelos autores (2017). 
Temáticas voltadas aos aspectos não comerciais da Gastronomia representam a maior parte da amostra. Os aspectos comerciais também estão presentes, mas os aspectos relacionados à saúde pouco se destacam. Três a cada cinco documentos que compuseram a amostra desta pesquisa versam sobre aspectos não comerciais do campo da Gastronomia.

Apesar das limitações do modelo, acreditase que ele retrata as tendências de temáticas e de abordagens nos estudos da Gastronomia atualmente. Mas vale ressaltar que o mesmo estará sujeito a alterações, consequência do surgimento de novas temáticas, respeitando a dinâmica natural de expansão como qualquer campo científico com o passar dos anos.

Por sua vez, a pesquisa científica é sempre resultado de um campo científico previamente estruturado que a produz, mas essa estrutura possui natureza dinâmica ao ponto de permitir a sua reconfiguração com a entrada de novos agentes de pesquisa e suas contribuições (Bourdieu, 1976).

A partir disso, entende-se que a própria natureza multi e interdisciplinar do fenômeno da Gastronomia permite a contínua expansão do seu campo científico sob a ótica de outras disciplinas ou campos científicos mais estruturados, sendo um dos exemplos a própria Hospitalidade (Bourdieu, 1976).

Vale lembrar também que a (re)configuração do campo científico também está condicionada, analogamente ao espaço curricular, aos interesses de órgãos públicos e privados com fins educacionais e de pesquisa, como universidades, associações, grupos e seminários de pesquisa, órgãos regulamentadores (como exemplo do MEC e da CAPES), Conselhos e fundações de amparo a pesquisas (CNPq, FAPESP, etc.).

\section{CONSIDERAÇÕES FINAIS}

A Gastronomia sempre foi destacada por pesquisadores pela sua natureza multi e interdisciplinar. A consequência desse fato é a geração de um campo científico aberto à exploração de seus conteúdos por espectros distintos e até mesmo incompreensíveis uns aos outros. Entende-se esse fenômeno desordenado como benéfico para a Gastronomia ao compreender a necessidade de constituir um corpo robusto o suficiente para posterior coesão e sistematização do que foi produzido. Fica claro com os resultados dessa pesquisa que a Gastronomia é um campo científico emergente no Brasil e que a produção neste campo está em consonância com sua própria natureza multi e interdisciplinar.

Para tanto, organizar o conhecimento de um campo apresentou-se inicialmente como um desafio, visto a magnitude da produção científica sobre a Gastronomia, mas antagonicamente imprescindível para amparar o contínuo aprimoramento desse campo e até mesmo de campos correlatos, como o da Hospitalidade e do Turismo, que se apresentam como os principais atores contribuintes. Foi necessário, antes de tudo, entender as contribuições de Bourdieu sobre "campo" e percorrer o surgimento e a configuração atual do seu ensino nas escolas superiores, para então iniciar uma nova interpretação da Gastronomia como um campo científico.

O primeiro obstáculo se resumiu na própria inconsistência sobre o conceito de Gastronomia entre os pesquisadores. Diversos autores utilizam palavras como cozinha, culinária e alimentação, por exemplo, como sinonímia de Gastronomia. Assim, adotou-se como premissa, com base em fundamentos teóricos, que a Gastronomia seria representante das demais palavras neste campo, como exemplos: alimentação, comensalidade e refeição.

Apesar de alguns contratempos, a pesquisa apresentou resultados que auxiliaram a visualizar uma proposta de configuração do campo. A Gastronomia foi contemplada como tema em 223 pesquisas realizadas em 76 instituições de ensino, em 7 das 9 grandes áreas do conhecimento e em 27 áreas diferentes, entre as quais a área "Interdisciplinar" se apresentou como a segunda mais expressiva, logo abaixo de "Turismo".

$\mathrm{Na}$ análise das categorias a posteriori, que envolveu a análise de conteúdo qualitativa, foi possível vislumbrar as temáticas ligadas a cada uma das áreas contempladas na amostra. Mas é necessário destacar as dificuldades de coletar todas as informações utilizando somente a UC Resumo. Por muitas vezes foi necessário recorrer ao capítulo de Introdução dos documentos para extrair informações não contidas no Resumo, dificuldade essa já apontada pelos autores da metodologia de estado da Arte.

Sugeriu-se o modelo como uma configuração preliminar do campo científico da Gastronomia. Seu caráter preliminar é consequência de o estudo ter sido restrito às teses e às dissertações, não levando em consideração outros elementos que compõem e 
influenciam campos científicos, como formação dos autores e orientadores, recursos financeiros desses pesquisadores para os projetos de pesquisa, restrições políticas-pedagógicas das linhas de pesquisas dos programas de pós-graduação stricto sensu, etc.

Ainda há um longo caminho a ser percorrido para uma configuração mais abrangente do campo da Gastronomia. Novas pesquisas poderão ser realizadas, como as centradas nos perfis dos autores desses documentos, nas relações de coprodução e orientação, na análise bibliométrica e qualitativa dos referenciais teóricos, estudar as dissertações e as teses de cada instituição para entender o contexto e os motivos das escolhas das temáticas. Contudo, acredita-se que os objetivos estabelecidos no início desta pesquisa foram alcançados, sendo de grande valia para o encaminhamento de pesquisas futuras sobre o campo da Gastronomia e outros campos.

\section{REFERÊNCIAS}

Bardin, L. (2011). Análise de conteúdo. São Paulo: Edições 70.

Bourdieu, P. (1976). Le champ scientifique. Actes de Ia Recherche en Sciences Sociales, 2/3, 88-104.

Bourdieu, P. (1998). O poder simbólico. Rio de Janeiro: Bertrand.

Bueno, M. L. (2016). Da Gastronomia francesa à Gastronomia global: hibridismos e identidades inventadas. Caderno CRH, 29 (78), 443-462.

Conselho Nacional de Educação. Resolução. (2002). Institui as Diretrizes Curriculares Nacionais Gerais para a organização e o funcionamento dos cursos superiores de tecnologia. Recuperado em 01 de janeiro de 2018, de http://portal.mec.gov.br/cne/arquivos/pdf/cp29. pdf.

Campos, J. R. V. (2001). A evolução da educação superior de graduação em hotelaria no Brasil: o caso Senac de São Paulo como referência na área. Dissertação de Mestrado, Universidade de São Paulo, São Paulo, São Paulo, Brasil.

Castro, H. C., Maciel, M. E., \& Maciel, R. A. (2016). Comida, cultura e identidade: conexões a partir do campo da gastronomia. Ágora, 18 (7), 18-27.

Collaço, J. H. (2013). Gastronomia: a trajetória de uma construção recente. Habitus, 11 (2), 203-222.

Fadul, E. M. C., Da Silva, M. A. M-A., \& Silva, L. P. (2012). Ensaiando interpretações e estratégias para o campo da administração pública no Brasil. Revista de Administração Pública, 46 (6), 1437-1458.

Ferreira, N. S. A. (2002). As pesquisas denominadas "estado da arte". Educação E Sociedade, 23 (79).
Gimenes-Minasse, M. H. S. G. (2012). Estudos sobre Gastronomia no Brasil: um estudo exploratóriodescritivo sobre dissertações de mestrado concluídas entre 2007 e 2011. Revista Rosa dos Ventos, 4 (3), 279-299.

Haden, R. (2015). Legend to Launchpad: Le Cordon Bleu, gastronomy and the future of education. In: Dredge, D.; Airey, D.; Gross, M. J. The Routledge handbook of tourism and hospitality education. (pp. 492504). United Kingdom: Routledge.

Jafari, J. (2005). El turismo como disciplina científica. Política y sociedad, 42 (1), 39-56.

Jafari, J. \& Ritchie, J. R. B. (1981). Toward new framework for tourism education - problems and prospects. Annals of Tourism Research, 8 (1), 13-34.

Ministério da Educação e Cultura. (2016). Catálogo Nacional de Cursos superiores de tecnologia. Recuperado em 01 de janeiro de 2018, de http:// portal.mec.gov.br/index.php?option $=\mathrm{com}_{-}$ docman\&view $=$ download $\&$ alias $=44501-\mathrm{cncst}-$ 2016-3edc-pdf\&category_slug $=$ junho-2016pdf\&Itemid $=30192$.

Mendes, B. C. \& Faleiros, P. B. (2013). O ensino da pesquisa científica em cursos superiores de Tecnologia em Gastronomia. Revista Hospitalidade, 10 (1).

Miyazaki, M. H. (2014). Ensino, pesquisa, extensão e a nova tipologia do ensino superior brasileiro. Anais do Seminário da Associação Nacional de Pós-graduação e Pesquisa em Educação, Caxambu, Brasil, 25.

Poulain J-P. (2002). Sociologies de l'alimentation. Paris: PUF.

Rocha, K. A. (2016). A evolução do curso de Gastronomia no Brasil. Contextos da Alimentação Revista de comportamento, cultura e sociedade. 4 (2).

Romanowski, J. P. \& Ens, R. T. (2006). As pesquisas denominadas do tipo "estado da arte" em educação. Diálogo Educ., 6 (19), 37-50.

Sogayar, R. L. \& Rejowski, M. (2014). Tourism, hospitality and events curriculum in higher education in Brazil: reality and challenges. In: Dredge, D.; Airey, D.; Gross, M. J. The Routledge handbook of tourism and hospitality education. (pp. 210224). Abingdon: Routledge.

Tribe, J. (1997). The indiscipline of tourism. Annals of tourism research, 24 (4), 638-657.

Tribe, J. (1999). The philosophic practitioner: tourism, knowledge and the curriculum. Tese de Doutorado, Institute of Education, University of London, Londres, UK. Contribuição de cada autor na elaboração do
artigo

Rafael Cunha Ferro: Texto (introdução, referencial, resultados, discussões e considerações), figuras, tabelas, quadros e revisão.

Mirian Rejowski: Orientação e revisão. 